\title{
Peritumoral plasmacytoid dendritic cells predict a poor prognosis for intrahepatic cholangiocarcinoma after curative resection
}

\author{
Zhi-Qiang Hu ${ }^{1,2 \dagger}$, Zheng-Jun Zhou ${ }^{1,2+}$, Chu-Bin Luo ${ }^{1,2}$, Hao-Yang Xin ${ }^{1,2}$, Jia Li ${ }^{1,2}$, Song-Yang Yu ${ }^{1,2}$ \\ and Shao-Lai Zhou ${ }^{1,2^{*}}$ (1)
}

\begin{abstract}
Background: Plasmacytoid dendritic cells (pDCs) are present in various primary and metastatic human neoplasms; however, their clinical significance in intrahepatic cholangiocarcinoma is not clear.

Methods: To evaluate pDCs' distributions in and around tumors as well as their potential function and predictive value for prognosis in patients undergoing curative resection, we performed immunohistochemistry to examine the expression of pDC marker BDCA2, and CD3, CD4, CD8 and Foxp3 in intratumoral and peritumoral tissues from 359 patients with intrahepatic cholangiocarcinoma and compared with prognostic and clinicopathologic factors.

Results: Results showed that patients with high numbers of $\mathrm{BDCA}^{+} \mathrm{pDCs}$ in peritumoral tissues were more likely to have elevated levels of carbohydrate antigen 19-9 and gamma-glutamyl transferase, larger and more tumors, advanced tumor-node-metastasis staging, more vascular/bile duct invasion, and lymphatic metastasis in association with greater chance of recurrence and shorter overall survival. Peritumoral tissues with larger numbers of pDCs also showed increased Foxp3 ${ }^{+}$regulatory $T$ cell infiltration, both of which were found to be independent factors for predicting time to recurrence and overall survival. By contrast, patient outcomes were not associated with the presence of intratumoral pDCs.
\end{abstract}

Conclusions: Peritumoral pDC infiltration may indicate an immune tolerogenic peritumor microenvironment and can be used to predict a poor prognosis for patients undergoing curative resection for intrahepatic cholangiocarcinoma.

Keywords: Plasmacytoid dendritic cells, Intrahepatic cholangiocarcinoma, Treg cells, Prognosis, Recurrence

\section{Introduction}

Intrahepatic cholangiocarcinoma (ICC) is one of most common types of cancer in the liver, second only to hepatocellular carcinoma, and the incidence of ICC continues to increase worldwide $[1,2]$. Curative resection for

\footnotetext{
*Correspondence: zhoushaolai99@sina.com

${ }^{\dagger}$ Zhi-Qiang Hu and Zheng-Jun Zhou contributed equally to this work 1 Liver Surgery Department, Liver Cancer Institute, Zhongshan Hospital, Fudan University, 136 Yi Xue Yuan Road, Shanghai 200032, China Full list of author information is available at the end of the article
}

ICC relies on early detection, such as by clinical screenings with advanced diagnostic techniques. Nevertheless, the high rate of ICC recurrence shortens the long-term survival of patients $[3,4]$. To better predict recurrence in patients after curative resection and enable more effective treatments, the molecular mechanisms contributing to disease recurrence and progression need to be elucidated.

The types and densities of immune and nonimmune stromal cells as well as their locations within the tumor microenvironment have been identified as prognostic

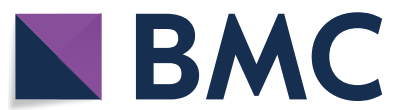

(c) The Author(s) 2020. This article is licensed under a Creative Commons Attribution 4.0 International License, which permits use, sharing, adaptation, distribution and reproduction in any medium or format, as long as you give appropriate credit to the original author(s) and the source, provide a link to the Creative Commons licence, and indicate if changes were made. The images or other third party material in this article are included in the article's Creative Commons licence, unless indicated otherwise in a credit line to the material. If material is not included in the article's Creative Commons licence and your intended use is not permitted by statutory regulation or exceeds the permitted use, you will need to obtain permission directly from the copyright holder. To view a copy of this licence, visit http://creativeco mmons.org/licenses/by/4.0/. The Creative Commons Public Domain Dedication waiver (http://creativecommons.org/publicdomain/ zero/1.0/) applies to the data made available in this article, unless otherwise stated in a credit line to the data. 
factors for several types of cancer [5-7]. Of note, ICC typically exhibits a prominent stromal reaction involving tissue-associated macrophages, tumor-associated neutrophils, and various types of $\mathrm{T}$ lymphocytes [8]. Immune/stromal cells are increasingly implicated in controlling invasive tumor growth and metastasis, resistance to chemotherapies and targeted agent therapies, and immunosuppression in patients with ICC [9].

Plasmacytoid dendritic cells (pDCs), which generate large amounts of type I interferon, represent a first line of defense against infection [10]. There is evidence that $\mathrm{pDCs}$ regulate $\mathrm{T}$ cell-mediated adaptive and innate immunity and thus likely contribute to cancer immunity $[11,12]$. pDCs are responsible for creating an immunosuppressive microenvironment in a variety of tumors [13]. For example, the immune tolerance induced by pDCs is crucial for the progression of ovarian cancers, and high numbers of pDCs in breast tumors are associated with dissemination and relapse $[14,15]$. Notably, the growth of tumors and their metastasis to bone tissues are suppressed when pDCs are depleted [16]. pDCs also influence the progression of multiple myeloma by promoting the survival and growth of tumors and contributing to chemotaxis and drug resistance [17].

Although pDCs have been observed in various tumor types, their distribution within these tumors and their potential interactions with other cells are largely unexplored [13]. To address this, we characterized the distribution of pDCs in ICC and determined if they can be associated with patient outcomes. Furthermore, we investigated the potential mechanism (s) by which pDCs regulate the immune microenvironment in ICC tumors.

\section{Materials and methods \\ Patients}

This study included 359 patients with ICC that underwent curative resection at Zhongshan Hospital, Fudan University, between 2009 and 2013. Patients were excluded from the analysis if they had palliative surgery or prior intervention (such as transhepatic artery embolization and chemo- or radiotherapy). Patients who developed another type of primary malignancy or inflammatory disease during the follow-up were also excluded. Informed consent was obtained from all participants, and the study was approved by the Research Ethics Committee of Zhongshan Hospital. Detailed information is provided in Table 1.

\section{Diagnostic criteria}

Diagnoses from histopathology were in accordance with World Health Organization criteria. Tumor differentiation was graded according to Edmondson and Steiner [18], and tumor staging was determined via
Table 1 Clinicopathologic characteristics of patients with intrahepatic cholangiocarcinoma $(n=359)$

\begin{tabular}{|c|c|}
\hline Characteristics & Number (\%) \\
\hline Age, year $(\leq 50$ versus $>50)$ & $74 / 285(20.6 / 79.4)$ \\
\hline Sex (female versus male) & $153 / 206(42.6 / 57.4)$ \\
\hline HBsAg (negative versus positive) & 252/107 (70.2/29.8) \\
\hline AFP, $\mathrm{ng} / \mathrm{ml}(\leq 20$ versus $>20)$ & $317 / 42(88.3 / 11.7)$ \\
\hline CA199 ( $\leq 36$ versus $>36)$ & $149 / 210(41.5 / 58.5)$ \\
\hline GGT,U/L ( $\leq 54$ versus > 54) & $172 / 187(47.9 / 52.1)$ \\
\hline Liver cirrhosis (no versus yes) & $273 / 86(76.0 / 24.0)$ \\
\hline Tumor size, $\mathrm{cm}$ ( $\leq 5$ versus $>5$ ) & $159 / 200(44.3 / 55.7)$ \\
\hline Tumor number (single versus multiple) & 258/101 (71.9/28.1) \\
\hline Microvascular/bile duct invasion (no versus yes) & $282 / 77(78.6 / 21.4)$ \\
\hline Lymphatic metastasis (no versus yes) & $306 / 53(85.2 / 14.8)$ \\
\hline Tumor encapsulation (complete versus none) & $62 / 297(17.3 / 82.7)$ \\
\hline Tumor differentiation (I+ II versus III + IV) & $181 / 178(50.4 / 49.6)$ \\
\hline TNM stage (I versus ||$+|||+| \mathrm{V})$ & $182 / 177(50.7 / 49.3)$ \\
\hline
\end{tabular}

AFP alpha-fetoprotein, GGT gamma glutamyl transferase, CA 19-9 carbohydrate antigen 19-9, TNM tumor-node-metastasis

tumor-node-metastasis (TNM) grading according to the 2017 guidelines of the International Union Against Cancer. Liver functioning was assessed via Child-Pugh scoring [19].

\section{Clinical outcomes}

Patients were monitored after the procedure as described previously [20]. Overall survival (OS) was defined as the time from the surgery until death or the final followup, when data from surviving patients were censored, in December of 2018. Time to recurrence (TTR) was defined as the time from the surgery until intrahepatic recurrence or extrahepatic metastasis was diagnosed [21].

\section{Immunohistochemical analyses}

Immunohistochemistry was performed on tissue microarrays comprising two 2-mm-diameter biopsy samples (spots) of 359 intratumoral and 322 peritumoral tissues. The absence of necrotic or hemorrhagic damage was confirmed by hematoxylin and eosin staining.

After antigen retrieval, tissue sections were incubated overnight at $4{ }^{\circ} \mathrm{C}$ with the following antibodies: antihuman blood dendritic cell antigen 2 (anti-BDCA2) (1:200; Abnova), anti-CD3 (clone F7.2.38) and anti-CD8 (clone C8/144B) (1:50; DakoCytomation), anti-CD4 (clone EPR6855) (1:100; Epitomics), and Foxp3 (clone 236A/E7) (1:100, Abcam). The sections were then incubated for $30 \mathrm{~min}$ at $37{ }^{\circ} \mathrm{C}$ with horseradish-peroxidase secondary antibodies from the EnVision Detection kit (GK500705, Gene Tech, China) and visualized by reacting 
with 3,3'-diaminobenzidine after avidin-biotin-mediated amplification, as described previously [22]. Mayer's hematoxylin was used for counterstaining. Omission of the primary antibody served as a negative control.

The numbers of immunopositive cells in each tissue spot were quantified by three investigators blinded to the sample identification and expressed as mean number ( \pm standard deviation) of cells/spot of the triplicate results. In subsequent analyses, the medians were used as the cutoff values unless specified otherwise. Thus, for $\mathrm{BDCA}+\mathrm{pDCs}$, those with $\leq 28$ cells/spot were assigned to the $\mathrm{pDCs}^{\text {low }}$ group, and those with $>28$ cells/spot were assigned to the $\mathrm{pDCs}{ }^{\text {high }}$ group. For Foxp $3+\mathrm{T}$ regulatory (Treg) cells, those with $\leq 7$ cells/spot were assigned to the Tregs ${ }^{\text {low }}$ group, and those with $>7$ cells/spot were assigned to the Tregs ${ }^{\text {high }}$ group.

\section{Statistical analysis}

Differences in the numbers of immunopositive cells between groups were assessed with unpaired-sample $t$ tests. To evaluate associations between immunohistochemistry results and clinical characteristics, Chi square and Fisher's exact tests were performed. Correlations were evaluated by means of Spearman's rho coefficients. OS and cumulative recurrence rates were analyzed with the Kaplan-Meier method and log-rank test. Univariate and multivariate analyses were performed via Cox proportional hazards regression. All analyses were performed with SPSS 16.0 statistical software. A $p$ value of $<0.05$ was considered statistically significant.

\section{Results}

Peritumoral pDC abundance in ICC patients correlates with clinicopathologic features

BDCA2-immunopositive pDCs were more abundant in peritumoral tissue than in intratumoral areas $(48.3 \pm 55.4$ cells/spot vs. $39.3 \pm 62.8$ cells/spot, respectively; $p<0.05$ ) (Fig. 1a, b). The number of peritumoral pDCs was significantly positively correlated with carbohydrate antigen $19-9$ and gamma-glutamyl transferase levels $(p=0.025$ and $p=0.01$, respectively), tumor size $(p=0.007)$, tumor number $(p=0.043)$, degrees of vascular/bile duct invasion and lymphatic metastasis $(p=0.045$ and $p=0.018$, respectively), and TNM stage $(p=0.002)$ (Table 2$)$. By contrast, sex was the only clinical characteristic that correlated with the number of pDCs in intratumoral tissues.

\section{Peritumoral pDC accumulation in ICC patients is a predictor of poor prognosis}

At the time of the final follow-up examination, $68.2 \%(245 / 359)$ of the patients had died, and $49.6 \%$ (178/359) had experienced recurrence. The 1-, 3-, and 5-year rates were $65.7 \%, 42.3 \%$, and $33.8 \%$, respectively, for OS and $34.8 \%, 51.6 \%$, and $58.7 \%$ for cumulative recurrence.

We next classified patients according to the number of peritumoral pDCs: those with $\leq 28$ cells/spot were assigned to the $\mathrm{pDCs}{ }^{\text {low }}$ group, and those with $>28$ cells/spot were assigned to the $\mathrm{pDCs}^{\text {high }}$ group. Patients in the $\mathrm{pDCs}{ }^{\text {low }}$ group had significantly higher 1-, 3-, and 5-year OS rates than those in the $\mathrm{pDCs}^{\text {high }}$ group (75.9\% versus 59.6\%, 56.4\% versus $32.4 \%$, and $46.4 \%$ versus $24.9 \%$, respectively) (Fig. 1c). Patients in the $\mathrm{pDCs}^{\text {high }}$ group also showed higher cumulative recurrence rates at 1,3 , and 5 years than those in the $\mathrm{pDCs}^{\text {low }}$ group $(41.0 \%$ versus $29.0 \%, 64.7 \%$ versus $38.4 \%$, and $69.5 \%$ versus $48.2 \%$, respectively) (Fig. 1c). Additionally, peritumoral pDCs were associated with OS and cumulative recurrence rates in patients with early-stage (TNM stage I) ICC $(n=182)$ and normal carbohydrate antigen 19-9 levels $(\leq 36 \mathrm{ng} / \mathrm{ml}, n=149)$ (Additional file 1: Figure S1). Of note, OS and cumulative recurrence rates were not associated with the number of intratumoral pDCs (Fig. 1c).

In the univariate analysis, prolonged TTR and OS were associated with a lower number of peritumoral pDCs in addition to various clinicopathologic factors (Table 3). The multivariate analysis revealed that the abundance of peritumoral pDCs, along with tumor number, lymphatic metastasis, and tumor encapsulation, was an independent factor for OS $(p=0.002$, hazard ratio $[\mathrm{HR}]=1.55)$ and TTR $(p=0.01, \mathrm{HR}=1.54)$ (Table 3$)$.

\section{pDC accumulation is associated with Treg abundance in peritumoral tissues}

To examine the association between pDCs and $\mathrm{T}$ cellmediated immune responses, $\mathrm{T}$ lymphocytes in peritumoral tissues were immunostained (Fig. 2a). The number of Foxp $3^{+}$Tregs was significantly positively correlated with the number of peritumoral pDCs $(p<0.001$, $R=0.291$ ) (Fig. 2b). However, the numbers of $\mathrm{CD}^{+}$, $\mathrm{CD}^{+}$, and $\mathrm{CD}^{+}$lymphocytes were not correlated (Additional file 2: Table S1).

\section{Combination of peritumoral pDC and Treg abundance for predicting ICC patient outcomes}

As the numbers of pDCs and Tregs were correlated, we evaluated the prognostic value of these factors combined. We compared the prognoses of ICC patients categorized into three groups according to peritumoral cell abundance: $\mathrm{pDCs}^{\text {low }} /$ Tregs $^{\text {low }}, \mathrm{pDCs}^{\text {low }} /$ Tregs $^{\text {high }}$ or $\mathrm{pDCs}^{\text {high }} /$ Tregs $^{\text {low }}$, and $\mathrm{pDCs}^{\text {high }} /$ Tregs $^{\text {high }}$. The 1-, 3-, and 5-year OS rates for the patients in the $\mathrm{pDCs}{ }^{\text {high }} /$ Tregs $^{\text {high }}$ group were $60.2 \%, 29.1 \%$, and $21.3 \%$, respectively, which were significantly lower than for those in the $\mathrm{pDCs}{ }^{\text {low }} /$ Tregs $^{\text {low }}$ group $(74.9 \%, 56.8 \%$, and $50.8 \%$, respectively) (Fig. 3a-c). Similarly, the 1-, 3-, and 5-year cumulative recurrence 

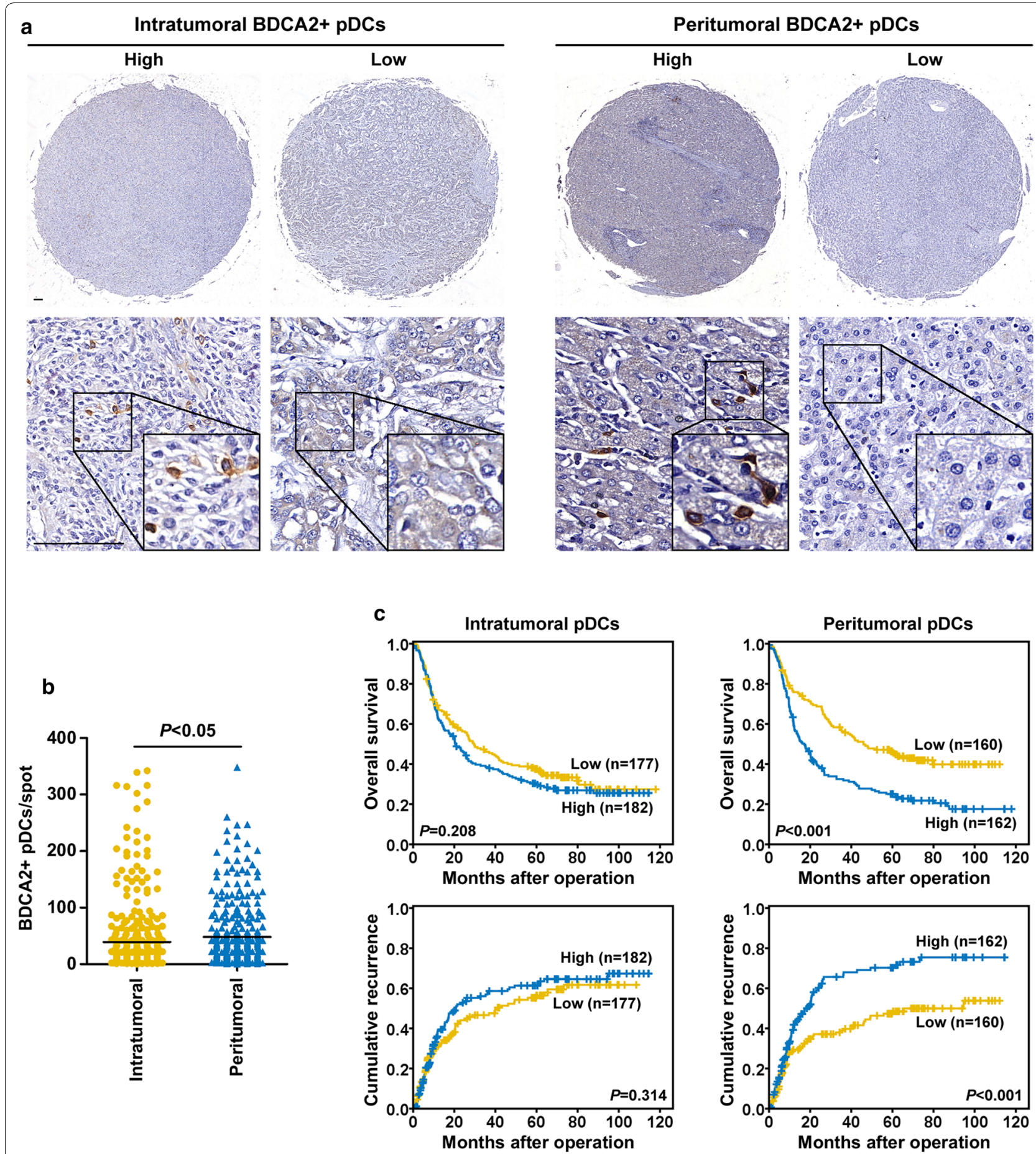

Fig. 1 pDC distribution in biopsy samples and the association with ICC prognosis. a Representative ICC tumor samples showing BDCA2 ${ }^{+}$pDCs in tumoral and peritumoral tissues. Scale bar, $100 \mu \mathrm{m}$. b pDCs were more abundant in peritumoral tissues than in intratumoral areas. c Prognostic value of pDCs in tumoral and peritumoral tissues of ICC patients 
Table 2 Correlation between intratumoral and peritumoral plasmacytoid dendritic cells (pDCs) and clinicopathologic characteristics in ICC ( $n=359$ for intratumoral tissues, 322 for peritumoral tissues)

\begin{tabular}{|c|c|c|c|c|c|c|}
\hline \multirow[t]{2}{*}{ Clinicopathological indexes } & \multicolumn{3}{|c|}{ Intratumoral pDCs } & \multicolumn{3}{|c|}{ Peritumoral pDCs } \\
\hline & Low & High & $\mathbf{P}$ & Low & High & $\mathbf{P}$ \\
\hline \multicolumn{7}{|l|}{ Age (year) } \\
\hline$\leq 50$ & 32 & 42 & 0.242 & 32 & 36 & 0.625 \\
\hline$>50$ & 145 & 140 & & 128 & 126 & \\
\hline \multicolumn{7}{|l|}{ Sex } \\
\hline Female & 85 & 68 & 0.041 & 75 & 61 & 0.094 \\
\hline Male & 92 & 114 & & 85 & 101 & \\
\hline \multicolumn{7}{|l|}{$\mathrm{HBsAg}$} \\
\hline Negative & 124 & 128 & 0.955 & 110 & 116 & 0.576 \\
\hline Positive & 53 & 54 & & 50 & 46 & \\
\hline \multicolumn{7}{|l|}{ CA199 } \\
\hline$\leq 36$ & 78 & 71 & 0.331 & 78 & 59 & 0.025 \\
\hline$>36$ & 99 & 111 & & 82 & 103 & \\
\hline \multicolumn{7}{|l|}{ AFP $(n g / m l)$} \\
\hline$\leq 20$ & 157 & 160 & 0.816 & 145 & 141 & 0.307 \\
\hline$>20$ & 20 & 22 & & 15 & 21 & \\
\hline \multicolumn{7}{|l|}{ GGT (U/L) } \\
\hline$\leq 54$ & 80 & 92 & 0.310 & 89 & 67 & 0.010 \\
\hline$>54$ & 97 & 90 & & 71 & 95 & \\
\hline \multicolumn{7}{|l|}{ Liver cirrhosis } \\
\hline No & 138 & 135 & 0.400 & 120 & 127 & 0.471 \\
\hline Yes & 39 & 47 & & 40 & 35 & \\
\hline \multicolumn{7}{|l|}{ Tumor size (cm) } \\
\hline$\leq 5$ & 74 & 85 & 0.351 & 84 & 61 & 0.007 \\
\hline$>5$ & 103 & 97 & & 76 & 101 & \\
\hline \multicolumn{7}{|l|}{ Tumor number } \\
\hline Single & 130 & 128 & 0.511 & 122 & 107 & 0.043 \\
\hline Multiple & 47 & 54 & & 38 & 55 & \\
\hline \multicolumn{7}{|l|}{ Vascular/bile duct invasion } \\
\hline Absence & 132 & 150 & 0.070 & 134 & 121 & 0.045 \\
\hline Present & 45 & 32 & & 26 & 41 & \\
\hline \multicolumn{7}{|l|}{ Lymphatic metastasis } \\
\hline No & 152 & 154 & 0.736 & 145 & 132 & 0.018 \\
\hline Yes & 25 & 28 & & 15 & 30 & \\
\hline \multicolumn{7}{|l|}{ Tumor encapsulation } \\
\hline Complete & 37 & 25 & 0.072 & 32 & 23 & 0.167 \\
\hline None & 140 & 157 & & 128 & 139 & \\
\hline \multicolumn{7}{|l|}{ Tumor differentiation } \\
\hline$I+\|$ & 93 & 88 & 0.427 & 90 & 79 & 0.179 \\
\hline$I I I+I V$ & 84 & 94 & & 70 & 83 & \\
\hline \multicolumn{7}{|l|}{ TNM stage } \\
\hline 1 & 90 & 92 & 0.955 & 97 & 70 & 0.002 \\
\hline$I I+I I I+I V+I V$ & 87 & 90 & & 63 & 92 & \\
\hline
\end{tabular}

The italic numerals indicate $P$ value $<0.05$

AFP alpha-fetoprotein, GGT gamma glutamyl transferase, CA 19-9 carbohydrate antigen 19-9, TNM tumor-node-metastasis

Chi square tests for all analyses 
Table 3 Univariate and multivariate analyses of prognostic factors in ICC $(n=359)$

\begin{tabular}{|c|c|c|c|c|}
\hline \multirow[t]{2}{*}{ Variable } & \multicolumn{2}{|l|}{ TTR } & \multicolumn{2}{|l|}{ os } \\
\hline & $\mathrm{HR}(95 \% \mathrm{Cl})$ & $P$ & $\mathrm{HR}(95 \% \mathrm{CI})$ & $\mathbf{P}$ \\
\hline \multicolumn{5}{|l|}{ Univariate analysis } \\
\hline Age, year $(\leq 50$ versus $>50)$ & $0.89(0.63-1.28)$ & 0.551 & $1.29(0.94-1.78)$ & 0.116 \\
\hline Sex (female versus male) & $1.04(0.77-1.39)$ & 0.809 & $1.07(0.83-1.38)$ & 0.583 \\
\hline HBsAg (negative versus positive) & $1.09(0.80-1.50)$ & 0.577 & $0.72(0.54-0.96)$ & 0.025 \\
\hline AFP, ng/ml ( $\leq 20$ versus $>20)$ & $1.17(0.76-1.79)$ & 0.483 & $0.84(0.56-1.26)$ & 0.396 \\
\hline CA199 ( $\leq 36$ versus > 36) & $1.19(0.88-1.60)$ & 0.258 & $1.90(1.46-2.48)$ & 0 \\
\hline GGT,U/L ( $\leq 54$ versus > 54) & $1.35(1.00-1.81)$ & 0.05 & $1.92(1.48-2.48)$ & 0 \\
\hline Liver cirrhosis (no versus yes) & $1.16(0.83-1.62)$ & 0.396 & $0.83(0.61-1.12)$ & 0.226 \\
\hline Tumor size, $\mathrm{cm}$ ( $\leq 5$ versus $>5$ ) & $1.38(1.02-1.86)$ & 0.035 & $1.65(1.28-2.14)$ & 0 \\
\hline Tumor number (single versus multiple) & $2.48(1.81-3.40)$ & 0 & $2.66(2.03-3.47)$ & 0 \\
\hline Microvascular/bile duct invasion (no versus yes) & $1.02(0.70-1.48)$ & 0.937 & $1.48(1.10-1.97)$ & 0.009 \\
\hline Lymphatic metastasis (no versus yes) & $2.23(1.52-3.28)$ & 0 & $2.70(1.96-3.72)$ & 0 \\
\hline Tumor encapsulation (complete versus none) & $1.91(1.20-3.04)$ & 0.006 & $1.46(1.01-2.11)$ & 0.042 \\
\hline Tumor differentiation (I + II versus III + IV) & $1.10(0.82-1.48)$ & 0.519 & $1.43(1.11-1.84)$ & 0.005 \\
\hline TNM stage (I versus II+ III + IV) & $1.92(1.42-2.59)$ & 0 & $2.78(2.14-3.61)$ & 0 \\
\hline Intra-pDCs (low versus high) & $1.16(0.87-1.56)$ & 0.314 & $1.18(0.91-1.51)$ & 0.208 \\
\hline Peri-pDCs (low versus high) & $1.77(1.29-2.44)$ & 0 & $1.87(1.42-2.46)$ & 0 \\
\hline Peri-Tregs (low versus high) & $1.63(1.19-2.24)$ & 0.003 & $1.53(1.17-2.01)$ & 0 \\
\hline Peri-pDCs and Tregs (both low vs. both high) & $2.22(1.49-3.31)$ & 0 & $2.17(1.55-3.03)$ & 0 \\
\hline \multicolumn{5}{|l|}{ Multivariate analysis } \\
\hline HBsAg (negative versus positive) & NA & NA & $0.70(0.51-0.97)$ & 0.033 \\
\hline CA199 ( $\leq 36$ versus > 36) & NA & NA & $1.35(1.01-1.82)$ & 0.045 \\
\hline GGT, U/L ( $\leq 54$ versus $>54)$ & NA & NA & $1.65(1.24-2.21)$ & 0.001 \\
\hline Tumor size, $\mathrm{cm}$ ( $\leq 5$ versus $>5$ ) & $1.05(0.75-1.46)$ & 0.786 & $1.13(0.84-1.51)$ & 0.435 \\
\hline Tumor number (single versus multiple) & $1.94(1.36-2.77)$ & 0 & $2.12(1.57-2.86)$ & 0 \\
\hline Microvascular/bile duct invasion (no versus yes) & NA & NA & $1.28(0.91-1.79)$ & 0.153 \\
\hline Lymphatic metastasis (no versus yes) & $1.72(1.12-2.64)$ & 0.014 & $2.09(1.45-3.00)$ & 0 \\
\hline Tumor encapsulation (complete versus none) & $1.96(1.18-3.25)$ & 0.009 & $1.58(1.04-2.42)$ & 0.034 \\
\hline Tumor differentiation (I+ II versus III + IV) & NA & NA & $1.32(1.00-1.74)$ & 0.051 \\
\hline Peri-pDCs (low versus high) & $1.54(1.11-2.14)$ & 0.01 & $1.55(1.17-2.05)$ & 0.002 \\
\hline Peri-Tregs (low versus high) & $1.59(1.16-2.20)$ & 0.004 & $1.34(1.02-1.77)$ & 0.036 \\
\hline Peri-pDCs and Tregs (both low vs. both high) & $1.96(1.30-2.94)$ & 0.001 & $1.74(1.23-2.47)$ & 0.002 \\
\hline
\end{tabular}

The italic numerals indicate $P$ value $<0.05$

Cox proportional hazards regression model

AFP alpha-fetoprotein, GGT gamma glutamyl transferase, CA 19-9 carbohydrate antigen 19-9, TNM tumor-node-metastasis, HR hazard ratio, CI confidential interval

rates for patients in the $\mathrm{pDCs}^{\text {high }} /$ Tregs $^{\text {high }}$ group $(42.4 \%$, $67.6 \%$, and $73.0 \%$, respectively) were significantly higher than for those in the $\mathrm{pDCs}^{\text {low }} /$ Tregs $^{\text {low }}$ group $(26.3 \%$, $35.8 \%$, and $43.5 \%$, respectively).

\section{Discussion}

Immune cell abundance is linked to the prognoses of patients with various cancers $[6,23]$. Here, we identified peritumoral $\mathrm{pDCs}$ as a novel factor for predicting clinical outcomes in patients with ICC. Specifically, a high abundance of pDCs in tissues surrounding the tumor was associated with a shorter OS and greater chance for recurrence. Therefore, pDCs should be examined in biopsy samples taken from patients undergoing curative resection for ICC to identify those at risk for recurrence and reduced survival.

pDCs are phenotypically distinguishable from other dendritic cells [11] and have been detected by immunohistochemical analyses of frozen samples from many types of cancers [13]. In the present study, we utilized a large clinical cohort for which clinical characteristics were known, enabling an investigation of the 

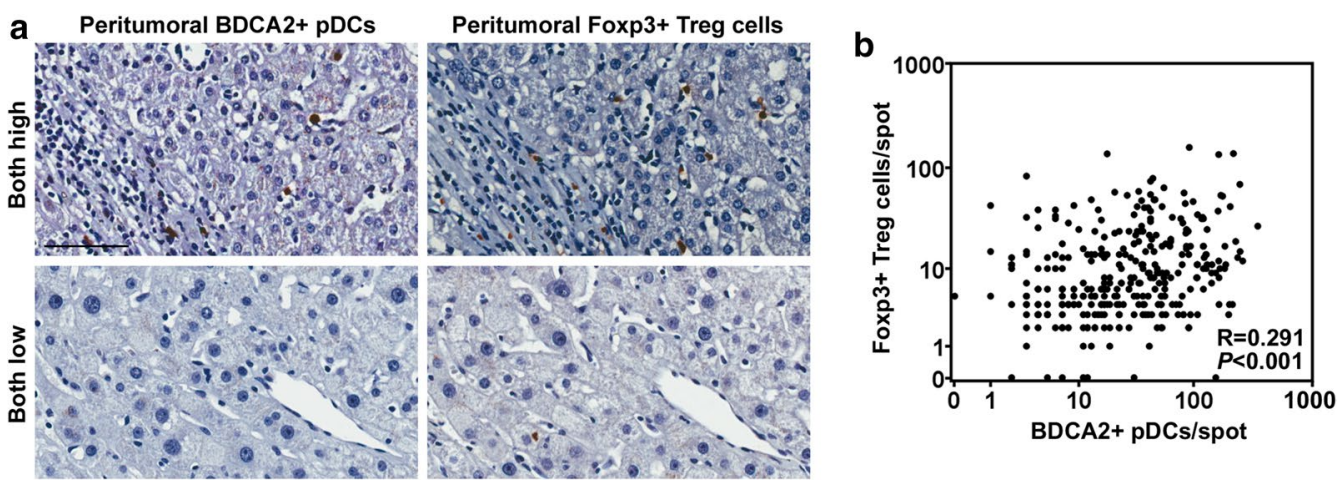

Fig. 2 Correlation between peritumoral pDC and Treg abundance. a High and low infiltration of peritumoral pDCs and Tregs. Scale bar, $100 \mu \mathrm{m}$. $\mathbf{b}$ Scatterplots showing significant positive correlations between $B D C A 2^{+} \mathrm{pDC}$ and Tregs in peritumoral tissues
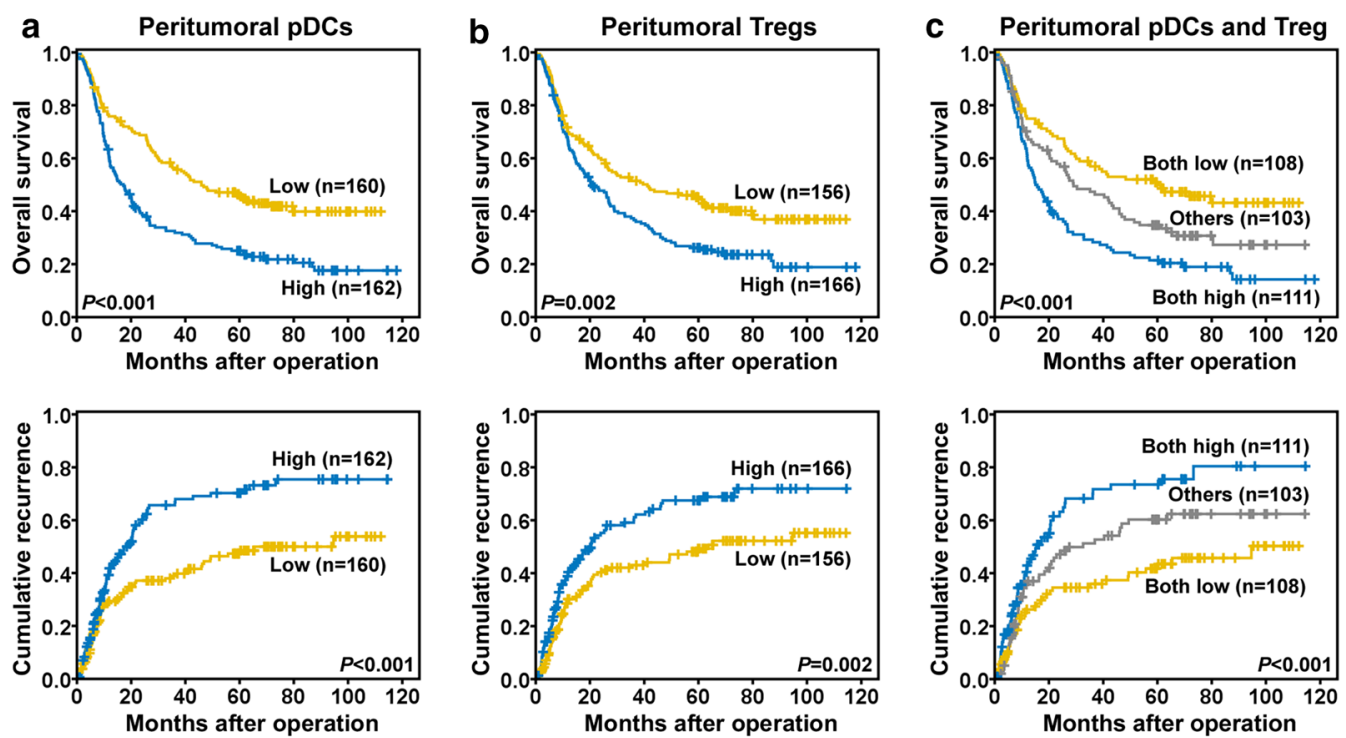

Fig. 3 Prognostic values of peritumoral pDC and Treg accumulation in ICC patients. Prognostic value of pDCs (a), Tregs (b), and pDCs plus Tregs (c) in peritumoral tissues of ICC patients

association between immunohistopathology and prognosis. Moreover, we identified pDCs by using a highly specific and sensitive monoclonal antibody against BDCA2, a member of the C-type lectin family of transmembrane glycoproteins $[13,24,25]$, rather than an anti-CD123 antibody, which labels several other cell types [13]. This enabled us to precisely quantify pDCs and assess their clinical significance. We also identified colocalization of BDCA2 and CD123 on most cell surfaces (Additional file 3: Figure S2), which further suggested that BDCA2 is specific to TA-pDCs in HCC. We found that the infiltration of large numbers of pDCs into peritumoral tissues correlated with tumor size and number, vascular/bile duct invasion, lymphatic metastasis, and TNM stage. More importantly, we found that this infiltration is a predictor of TTR and OS, highlighting the importance of the peritumoral microenvironment in ICC progression.

High rates of recurrence or metastasis result in unsatisfactory long-term survival of ICC patients after curative resection [3]. The peritumoral liver tissues were the major target organ of ICC metastasis or recurrence, which was also be classified as intrahepatic recurrence. This peritumoral liver tissue is also reportedly useful for examining intrahepatic recurrence by assessing mechanisms related to immune responses and inflammation $[26,27]$. These findings support the "seed and soil" hypothesis of Paget, in which the "seeds" of metastasis can only grow in favorable soil, which includes the target microenvironment $[28,29]$. The rate-limiting steps of 
metastasis or recurrence are tumor cell survival, extravasation, and establishment in the target organ. Consistent with the importance of this microenvironment, we found that the presence of peritumoral pDCs was an independent predicator of ICC prognosis, whereas the presence of intratumor PDCs was not. Together, this demonstrates the prognostic value of the peritumoral microenvironment in metastasizing target organs.

As peri/intratumoral dendritic cells can present tumorassociated antigens to naive $\mathrm{T}$ cells, they are thought to trigger an antitumor immune response [30]. Although pDCs synthesize interferon, they do not produce enough to kill cancerous cells due to a lack of appropriate stimuli in the tumor microenvironment or to active suppression [13]. Nevertheless, pDCs stimulate the differentiation and expansion of Tregs in vitro and induce Tregs in the periphery in vivo $[31,32]$. pDCs have been reported to be capable of directly activating mature Tregs through expression of the enzyme indoleamine 2,3-dioxygenase (IDO). This activation is MHC restricted, requires an intact amino acid-responsive GCN2 pathway in the Tregs, and can be prevented by CTLA4 blockade [33, 34]. Some other reports have also suggested that ICOSL is expressed by pDCs and can interact with ICOS expressed on naïve $\mathrm{CD} 4+\mathrm{T}$ cells to induce their differentiation into IL-10-producing Tregs $[35,36]$. In addition, impaired IFN- $\alpha$ production by pDCs was also shown to be involved in promoting regulatory $\mathrm{T}$ cell expansion [37]. However, tumor-infiltrating Tregs may contribute to immune tolerance, as they are associated with the invasiveness and prognosis of most cancer types [6,38]. Consistent with this, the numbers of pDCs and Tregs in tissues surrounding ICC tumors were correlated with each other and with patient prognosis. By contrast, the accumulation of pDCs within the tumors was not significantly correlated with the numbers of Tregs or prognosis, suggesting that the immunotolerant peritumoral microenvironment is the crucial factor determining ICC outcome.

Although the high recurrence rate of ICC necessitates the ability to predict recurrence, biomarkers for ICC recurrence are lacking. The identification of recurrence predictors could be particularly beneficial to predict and prevent recurrence in early-stage ICC patients who experience relapse unexpectedly just after curative resection. These patients may have a better outcome if recurrence can be predicted early and prevented. Here, we showed that peritumoral pDC levels, may have prognostic ability in identifying these patients. Recurrence is more likely in early-stage or normal CA19-9 ICC patients with high levels of peritumoral pDCs, careful monitoring of such patients is advised.

\section{Conclusions}

We show that peritumoral accumulation of pDCs is a novel predictor of prognosis in patients with ICC undergoing curative resection, which may indicate an immune tolerogenic peritumor microenvironment induced by Foxp $3^{+}$ regulatory $\mathrm{T}$ cell infiltration. Future studies investigating therapeutic strategies targeting the anti-immune tolerogenic responses may provide better treatments for patients with ICC.

\section{Supplementary information}

Supplementary information accompanies this paper at https://doi. org/10.1186/s12935-020-01676-z.

Additional file 1: Figure S1 Prognostic value of peritumoral pDC in patients with early-stage (TNM stage I) ICC $(n=182)$ or normal carbohydrate antigen $19-9$ levels ( $\leq 36 \mathrm{ng} / \mathrm{ml}, n=149$ ).

Additional file 2: Table S1. Numbers of peritumoral CD3,$+ C D 4+$, and CD8+ T cells in ICC cohort and their correlations with pDCs $(n=322$ for peritumoral tissues).

Additional file 3: Figure S2 Fluorescence microscopy showed colocalization of BDCA2 and CD123 expression on cell surface.

\section{Abbreviations}

pDCs: Plasmacytoid dendritic cells; ICC: Intrahepatic cholangiocarcinoma; TNM: Tumor-node-metastasis; OS: Overall survival; TTR: Time to recurrence.

\section{Acknowledgements}

Not applicable.

\section{Authors' contributions}

$\mathrm{ZQH}$ and ZJZ performed the experiments; SLZ and ZQH analyzed the data; HYX, CBL, JL and SYY provided the samples; SLZ and ZQH wrote the paper; SLZ obtained funding and designed the research. All authors read and approved the final manuscript.

Funding

This study was jointly supported by the National Natural Science Foundation of China (No. 81972708; No. 81773069; No. 82072681, No. 82003082), the National Key R\&D Program of China (No. 2018YFA0109400), Shanghai RisingStar Program (18QA1401200) and Municipal Human Resources Development Program for Outstanding Young Talents in Medical and Health Sciences in Shanghai (2018YQ14).

\section{Availability of data and materials}

The datasets supporting the conclusions of this article are included within the article.

\section{Ethics approval and consent to participate}

This study was approved by the Research Ethics Committee of Zhongshan Hospital.

\section{Consent for publication}

Not applicable.

\section{Competing interests}

The authors disclose no conflicts.

\section{Author details}

${ }^{1}$ Liver Surgery Department, Liver Cancer Institute, Zhongshan Hospital, Fudan University, 136 Yi Xue Yuan Road, Shanghai 200032, China. ${ }^{2}$ Key Laboratory of Carcinogenesis and Cancer Invasion (Fudan University), Ministry of Education, Shanghai 200032, China. 
Received: 19 August 2020 Accepted: 24 November 2020

Published online: 04 December 2020

\section{References}

1. Siegel R, Ma J, Zou Z, Jemal A. Cancer statistics, 2014. CA Cancer J Clin. 2014;64(1):9-29.

2. Blechacz B, Gores GJ. Cholangiocarcinoma: advances in pathogenesis, diagnosis, and treatment. Hepatology. 2008;48(1):308-21.

3. Rizvi S, Gores GJ. Pathogenesis, diagnosis, and management of cholangiocarcinoma. Gastroenterology. 2013;145(6):1215-29.

4. Mavros MN, Economopoulos KP, Alexiou VG, Pawlik TM: Treatment and Prognosis for Patients With Intrahepatic Cholangiocarcinoma: Systematic Review and Meta-analysis. JAMA Surg 2014.

5. Galon J, Costes A, Sanchez-Cabo F, Kirilovsky A, Mlecnik B, Lagorce-Pages C, Tosolini M, Camus M, Berger A, Wind P, et al. Type, density, and location of immune cells within human colorectal tumors predict clinical outcome. Science. 2006;313(5795):1960-4.

6. Fridman WH, Pages F, Sautes-Fridman C, Galon J. The immune contex ture in human tumours: impact on clinical outcome. Nat Rev Cancer. 2012;12(4):298-306

7. Zhou SL, Yin D, Hu ZQ, Luo CB, Zhou ZJ, Xin HY, Yang XR, Shi YH, Wang Z, Huang XW, et al. A Positive Feedback Loop Between Cancer Stem-Like Cells and Tumor-Associated Neutrophils Controls Hepatocellular Carcinoma Progression. Hepatology. 2019;70(4):1214-30.

8. Sirica AE, Gores GJ, Groopman JD, Selaru FM, Strazzabosco M, Wang XW Zhu AX: Intrahepatic Cholangiocarcinoma: Continuing Challenges and Translational Advances. Hepatology 2018.

9. Sirica AE, Gores GJ. Desmoplastic stroma and cholangiocarcinoma: clinical implications and therapeutic targeting. Hepatology. 2014;59(6):2397-402.

10. Swiecki M, Colonna M. Unraveling the functions of plasmacytoid dendritic cells during viral infections, autoimmunity, and tolerance. Immunol Rev. 2010:234(1):142-62.

11. Lande R, Gilliet M. Plasmacytoid dendritic cells: key players in the initiation and regulation of immune responses. Ann NY Acad Sci. 2010;1183:89-103.

12. Swiecki M, Colonna M. The multifaceted biology of plasmacytoid dendritic cells. Nat Rev Immunol. 2015;15(8):471-85.

13. Vermi W, Soncini M, Melocchi L, Sozzani S, Facchetti F. Plasmacytoid dendritic cells and cancer. J Leukoc Biol. 2011;90(4):681-90.

14. Treilleux I, Blay JY, Bendriss-Vermare N, Ray-Coquard I, Bachelot T, Guastalla JP, Bremond A, Goddard S, Pin JJ, Barthelemy-Dubois C, et al. Dendritic cell infiltration and prognosis of early stage breast cancer. Clin Cancer Res. 2004;10(22):7466-74.

15. Labidi-Galy SI, Sisirak V, Meeus P, Gobert M, Treilleux I, Bajard A, Combes $J$ D, Faget J, Mithieux F, Cassignol A, et al. Quantitative and functional alterations of plasmacytoid dendritic cells contribute to immune tolerance in ovarian cancer. Cancer Res. 2011;71(16):5423-34.

16. Sawant A, Hensel JA, Chanda D, Harris BA, Siegal GP, Maheshwari A Ponnazhagan S. Depletion of plasmacytoid dendritic cells inhibits tumor growth and prevents bone metastasis of breast cancer cells. J Immunol. 2012;189(9):4258-65.

17. Chauhan D, Singh AV, Brahmandam M, Carrasco R, Bandi M, Hideshima T, Bianchi G, Podar K, Tai YT, Mitsiades C, et al. Functional interaction of plasmacytoid dendritic cells with multiple myeloma cells: a therapeutic target. Cancer Cell. 2009;16(4):309-23.

18. Wittekind C. Pitfalls in the classification of liver tumors. Pathologe 2006;27(4):289-93.

19. Heimbach JK, Kulik LM, Finn RS, Sirlin CB, Abecassis MM, Roberts LR, Zhu AX, Murad MH, Marrero JA. AASLD guidelines for the treatment of hepatocellular carcinoma. Hepatology. 2018;67(1):358-80.

20. Zhou SL, Zhou ZJ, Hu ZQ, Huang XW, Wang Z, Chen EB, Fan J, Cao Y, Dai Z, Zhou J:Tumor-Associated Neutrophils Recruit Macrophages and T-Regulatory Cells to Promote Progression of Hepatocellular Carcinoma and Resistance to Sorafenib. Gastroenterology 2016, 150 (7):1646-1658 e1617.
21. Zhou SL, Hu ZQ, Zhou ZJ, Dai Z, Wang Z, Cao Y, Fan J, Huang XW, Zhou J. miR-28-5p-IL-34-macrophage feedback loop modulates hepatocellular carcinoma metastasis. Hepatology. 2016;63(5):1560-75.

22. Zhou SL, Zhou ZJ, Hu ZQ, Li X, Huang XW, Wang Z, Fan J, Dai Z, Zhou J. CXCR2/CXCL5 axis contributes to epithelial-mesenchymal transition of HCC cells through activating PI3K/Akt/GSK-3beta/Snail signaling. Cancer Lett. 2015:358(2):124-35.

23. Grivennikov SI, Greten FR, Karin M. Immunity, inflammation, and cancer. Cell. 2010;140(6):883-99.

24. Boiocchi L, Lonardi S, Vermi W, Fisogni S, Facchetti F. BDCA-2 (CD303): a highly specific marker for normal and neoplastic plasmacytoid dendritic cells. Blood. 2013;122(2):296-7.

25. Dzionek A, Sohma Y, Nagafune J, Cella M, Colonna M, Facchetti F, Gunther G, Johnston I, Lanzavecchia A, Nagasaka T, et al. BDCA-2, a novel plasmacytoid dendritic cell-specific type II C-type lectin, mediates antigen capture and is a potent inhibitor of interferon alpha/beta induction. J Exp Med. 2001;194(12):1823-34

26. Hoshida Y, Villanueva A, Kobayashi M, Peix J, Chiang DY, Camargo A, Gupta S, Moore J, Wrobel MJ, Lerner J, et al. Gene expression in fixed tissues and outcome in hepatocellular carcinoma. N Engl J Med. 2008;359(19):1995-2004.

27. Budhu A, Forgues M, Ye QH, Jia HL, He P, Zanetti KA, Kammula US, Chen Y, Qin LX, Tang ZY, et al. Prediction of venous metastases, recurrence, and prognosis in hepatocellular carcinoma based on a unique immune response signature of the liver microenvironment. Cancer Cell. 2006;10(2):99-111.

28. Nguyen DX, Bos PD, Massague J. Metastasis: from dissemination to organspecific colonization. Nat Rev Cancer. 2009;9(4):274-84

29. Quail DF, Joyce JA. Microenvironmental regulation of tumor progression and metastasis. Nat Med. 2013;19(11):1423-37.

30. Lin A, Schildknecht A, Nguyen LT, Ohashi PS. Dendritic cells integrate signals from the tumor microenvironment to modulate immunity and tumor growth. Immunol Lett. 2010;127(2):77-84.

31. Matta BM, Castellaneta A, Thomson AW. Tolerogenic plasmacytoid DC. Eur J Immunol. 2010;40(10):2667-76.

32. Demoulin S, Herfs M, Delvenne P, Hubert P. Tumor microenvironment converts plasmacytoid dendritic cells into immunosuppressive/ tolerogenic cells: insight into the molecular mechanisms. J Leukoc Biol. 2013;93(3):343-52.

33. Gerlini G, Di Gennaro P, Mariotti G, Urso C, Chiarugi A, Pimpinelli N, Borgognoni L. Indoleamine 2,3-dioxygenase + cells correspond to the BDCA2 + plasmacytoid dendritic cells in human melanoma sentinel nodes. J Invest Dermatol. 2010;130(3):898-901.

34. Sharma MD, Baban B, Chandler P, Hou DY, Singh N, Yagita H, Azuma M, Blazar BR, Mellor AL, Munn DH. Plasmacytoid dendritic cells from mouse tumor-draining lymph nodes directly activate mature Tregs via indoleamine 2,3-dioxygenase. J Clin Invest. 2007;117(9):2570-82.

35. Ito T, Yang M, Wang YH, Lande R, Gregorio J, Perng OA, Qin XF, Liu YJ, Gilliet M. Plasmacytoid dendritic cells prime IL-10-producing $T$ regulatory cells by inducible costimulator ligand. J Exp Med. 2007;204(1):105-15.

36. Conrad C, Gregorio J, Wang YH, Ito T, Meller S, Hanabuchi S, Anderson S, Atkinson N, Ramirez PT, Liu YJ, et al. Plasmacytoid Dendritic Cells Promote Immunosuppression in Ovarian Cancer via ICOS Costimulation of Foxp3 + T-Regulatory Cells. Cancer Res. 2012;72(20):5240-9.

37. Sisirak V, Faget J, Gobert M, Goutagny N, Vey N, Treilleux I, Renaudineau S, Poyet G, Labidi-Galy SI, Goddard-Leon S, et al. Impaired IFN-alpha Production by Plasmacytoid Dendritic Cells Favors Regulatory T-cell Expansion That May Contribute to Breast Cancer Progression. Cancer Res. 2012;72(20):5188-97.

38. Fridman WH, Zitvogel L, Sautes-Fridman C, Kroemer G. The immune contexture in cancer prognosis and treatment. Nat Rev Clin Oncol. 2017:14(12):717-34

\section{Publisher's Note}

Springer Nature remains neutral with regard to jurisdictional claims in published maps and institutional affiliations. 